\title{
The Effect of Family Planning Use on Household Economy at Arbaminch Town, Gamo Goffa Zone, Southern Ethiopia
}

\author{
Amsale Tekle Ergano ${ }^{1}$, Girma Azene ${ }^{2}$, Mesfin Mamo ${ }^{3}$ \\ ${ }^{1}$ Institute of Public Management and Development Studies, Department of Economics, Ethiopian Civil Service University, Addis Ababa, \\ Ethiopia \\ ${ }^{2}$ Department of Economics, Tulane University Technical Assistant Project-Ethiopia, Addis Ababa, Ethiopia \\ ${ }^{3}$ Department of Nursing, College of Medicine and Health Sciences, Arbaminch University, Arba Minch, Ethiopia
}

Email address:

tekleamsale@ymail.com (A. T. Ergano), Girmachere@gmail.com (G. Azene), mefirich2007@yahoo.com (M. Mamo)

\section{To cite this article:}

Amsale Tekle Ergano, Girma Azene, Mesfin Mamo. The Effect of Family Planning Use on Household Economy at Arbaminch Town, Gamo Goffa Zone, Southern Ethiopia. Science Journal of Public Health. Vol. 4, No. 6, 2016, pp. 470-475. doi: 10.11648/j.sjph.20160406.19

Received: September 5, 2016; Accepted: September 21, 2016; Published: October 25, 2016

\begin{abstract}
Family planning (F/P) is a health measure which is regarded as cost-effective in the developing world. There is lack of empirical evidence that showed the effect of family planning use on the household's economy in Ethiopia and particularly in the study area. Thus, this study was conducted with the objective of investigating the effect of family planning use on the household economy in Arbaminch town. A cross-sectional study with both quantitative and qualitative approach was employed among a sample of 368 women using F/P during the month of March 2013. A probability sampling technique was used to select the respondents. A pre-tested interviewer administered structured questionnaire and an interview guide was used to collect data on the effect of family planning use. Data were analyzed using Statistical Package for Social Sciences (SPSS) version 16. Descriptive statistics, chi square test and binary logistic regressions were applied. Three hundred sixty eight women were included in this study making a response rate of $100 \%$. Of all the respondents, the proportion of women who observed and reported the overall increase on household income attributed to the use of F/P was only $41.8 \%$. The type of family planning method, the total number of children, the frequency of hospitalization and the reason for using family planning were some of the potential predictors of household income. Majority of clients had actually observed the effect of family planning in reducing their own fertility/family size. The long acting type of family planning method was identified as a factor affecting the overall household income. A strategy has to be designed to reach women who had less awareness about the effect of family planning in improving household economy. Policy makers and program planners should give due emphasis to the way how the coverage and utilization of long term family planning methods can be improved.
\end{abstract}

Keywords: Type of F/Puse, Household Economy (Income), Binary Logistic Regression

\section{Introduction}

Throughout the developing world, countries are making every effort to reduce poverty and reach the Millennium Development Goals. Many of these countries are also focusing to reduce the effect of uncontrolled population growth on health, economy and development. A rapid increase in population makes even modest gains in health, education, and employment difficult to achieve [1].

Population growth also put a pressure on the availability of natural resources such as land, water, forests, etc. One of the most important interventions to confront population growth and spur economic development is investing in family planning services. Most countries that have achieved rapid economic growth have also had a history of strong family planning programs that helped women effectively tackle and avoid unplanned pregnancies and to achieve a smaller family size that meets their desire and preferences [2]. According to the report of the Federal Ministry of Finance and Economy Development, the Ethiopian economy had registered a double-digit growth over the past years. This growth was observed as a result of inducing a combination of different factors such as modernization of agriculture, the development of new export sectors, strong global commodity demand, and effective government-led development investment. The level 
of poverty has declined from $45.5 \%$ in $1995 / 96$ to $29.6 \%$ in 2010/2011 [3]. Nevertheless, according to the plan made by the Ethiopian Government in 1993, for Ethiopia to be one of the middle-income countries, the population growth has to slow down by decreasing the total fertility rateto the level of 4 children per women by the year 2015 [4].

Furthermore, population growth resulting from such high fertility is believed to come at a high cost in the living standards of the people [5]. Because of this, an emphasis has to be given to the effect of family planning on household poverty/wellbeing and girls' schooling, which are mainly affected by high fertility. Though the effect of family planning on economic development at a national level was studied by different countries including developing countries, there were many challenges in measuring its potential effects.

For many reasons, evidences about the effect of family planning use on household economy are little. In the first place, the investigations about family planning use were conducted in the periods of rapid economic development and fertility decline, so that it was not easy to separate the effects of family planning on economy and fertility. Secondly, little emphasis was given on how family planning affects the life of women such as educational status. Evidence from the USA shows that there was a discrepancy between the educational status of women and their use of family planning [6, 7]. This discrepancy needs further investigation.

Here in Ethiopia the impact of family planning on economic development has not been well documented. As per the knowledge of investigators, there is lack of empirical evidence that shows the effect of family planning on the household's economy in Ethiopia and particularly in the study area. Thus, this study was designed to investigate the effect of family planning on the household economy in Arbaminch, Southern Ethiopia.

\section{Methods and Materials}

\subsection{Study Area and Setting}

A community based cross sectional study with both quantitative and qualitative methods of data collection was conducted in the month of March, 2013 in Arba Minch town, the capital of GammoGofa zone. The study area is located $505 \mathrm{~km}$ South-West from Addis Ababa, the capital of Ethiopia and 275 $\mathrm{km}$ away from Awassa, the capital of Southern Nations Nationalities and People Regional State (SNNPRS). It is a town with a total population of 88,890 , of which $45,333(51 \%)$ are females. Women of reproductive age group (15-49 years) are 17, 244(19.4\%). The town hosts one government hospital, two public health centers and forty-nine private health institutions. According to the Zonal Health Department report of 2012, the fertility rate of the town was 5.2. There were 9,546(53\%) married and family planning users in the town.

\subsection{Source and Study Population}

All married women living in Arbaminch town were the source population. Among the currently married women, all family planning users living in the town were the study population. After proportional allocation to the number of eligible women in each kebele, study units were identified with systematic sampling technique. Six sessions of focus group discussions (FGDs) were undertaken among purposively selected married men and women. The sample size for FGDs was determined based on information saturation. Each focus group discussion consisted of 6-8 members.

\subsection{Sample Size and Sampling Technique}

Sample size was computed by using stat cal program of EPI Info based on the following assumptions: $5 \%$ level of significance, $95 \%$ confidence level, $(0.53)$ proportion of $\mathrm{F} / \mathrm{P}$ use in the town. So that the final sample size was 368 .

\subsection{Method of Data Collection}

Both quantitative and qualitative data were collected. Quantitative data was collected through face to face interview by using pre-tested questionnaire. While qualitative data was collected through focus group discussion by using FGD guide. The questionnaire was initially prepared in English language then was translated into Amharic language by an expert who has good ability of both languages then again was translated back to English to check for any inconsistencies. The variables in the questionnaire were adapted from previous studies and literatures. The questionnaire was pretested on $5 \%$ of similar population in the nearby district. The data collectors were those who are able to communicate with the respondents using both Amharic and the local language, which is "Gammugna" language. Training was given for data collectors and supervisors for one day by the principal investigators to make them familiar with the data collection instrument.

\subsection{Variables}

\subsubsection{Dependent Variable}

Household Economy

\subsubsection{Independent Variables}

- Family planning factors: the main explanatory variable, which is measured in terms of type of F/P used, reason for F/P use and awareness about F/P by women.

- Socio-demographic variables: Age, ethnicity, religion, marital status, educational status, occupation, years of marriage and family size.

- Family planning and fertility (family size) factor:

- Variables related to maternal and child health status: type of illness, frequency of morbidity and that hospital admission.

- Family planning and household income factor: average monthly household income, main source of household income, impact of $\mathrm{F} / \mathrm{P}$ on the source and level of household income.

\subsection{Operational Definitions}

- Family planning use is the use of various methods of 
modern contraceptives based on informed decision making of women.

- Type of family planning: In this study the whole family planning methods are grouped into two. These are short acting and long acting based on the duration of the effect of family planning methods.

- Short acting F/P methods: are those modern contraceptive methods acting within a brief period of time starting from minutes to 1 year.

- Long acting F/P methods: are those modern contraceptive methods in which the effect of the contraceptives lasts for long period of time. That can act for more than one year and even for a life long time.

- Family size/household size: this refers to the number of individuals living together in one family or household.

- Morbidity: this is about the occurrence of any illness /any deviation from the normal state of health. In this study both the morbidity of mothers and children were computed.

- Hospitalization: this is about the experience of any admission to the hospital.

- Household economy: household economy is usually measured in terms of household assets, expenditure and income. In this study, it has been estimated by measuring only the household income.

- Actual increase in household income: this refers to a mere increase of household income observed and verbally reported by the woman after she became a F/P client. This is just a personal judgment of the respondents about their household income based on their perception where by the increment might not be mainly attributed to $\mathrm{F} / \mathrm{P}$.

- Overall increase in household income: this refers to the actual increase of household income observed and verbally reported by the woman after she became a F/P client. This is also a personal judgment of the respondents about their household income based on their perception where by the increment might be attributed mainly to F/P use.

\subsection{Data Quality Assurance}

To ensure the quality of data, an emphasis was given in the designing of data collection instrument for its simplicity and consistency. Training was given for the data collectors before the data was collected. Throughout the period of data collection, the data were reviewed and checked for completeness and relevance by the supervisors and investigators. The assurance of data quality was also maintained during data coding, entry, cleaning and analysis. The qualitative data were first transcribed then translated into English language before analysis.

\subsection{Data Analysis}

After the questionnaires were checked manually for completeness and consistencies, the data were coded and entered into SPSS version 16.0. Descriptive statistics was carried out for each of the variables. Bivariate and multivariate analysis was done by using binary logistic regression model. The Principal Investigators have focused their attention to the overall model evaluation, statistical tests of individual predictors, goodness-of-fit statistics, and validations of predicted probabilities. Data from the FGD was translated and transcribed to English and categorized accordingly to main thematic areas manually. We have read the data repeatedly. Finally the findings were triangulated with quantitative findings.

\subsection{Ethical Considerations}

Ethical clearance and permission was obtained from Ethiopian Civil Service University. Permission was also sought from the administrative bodies such as Gamo Goffa Zone Health Department and Arbaminch Town Health Office. Informed consent was obtained from each study participant.

\section{Results}

\subsection{Socio-demographic Characteristics}

In this study 368 respondents were participated, yielding a response rate of 100 percent. The age of the respondents ranged from 18 to 49 years with a mean of 33+ SD of 7.15. Out of the total respondents, 191(51.9\%) were within the age range of 34-49 years. Amongst the total respondents, $282(76.6 \%)$ were married and live together with their spouses and the remaining were grouped into married but not currently living together with their spouse followed by divorced and widowed. The average family size of the respondents was 5.7. The largest and the smallest family size of the respondents were 12 and 1 , respectively.

\subsection{Description of Clients by Their Family Planning Characteristics}

All respondents had awareness about family planning. Around $44 \%$ of them were familiar with the meaning of family planning as a means used to ensure child spacing followed by $(32.3 \%)$ of those who reported as a method of limiting number of children. The majority of women (96.5\%) reported the importance of family planning as a means of improving household economy, while the rest (3.5\%) had not acknowledged such importance about family planning.

The major proportions of women $(45.4 \%)$ were using injectable type of contraceptive method followed by Norplant (32\%). Almost all respondents (92.1\%) reported that their partners were not using any type of contraceptive method. Over half of the women (52.7\%) were using short acting contraceptive methods, while the remaining(47.3\%) were using long acting (Shown in figure 1). 


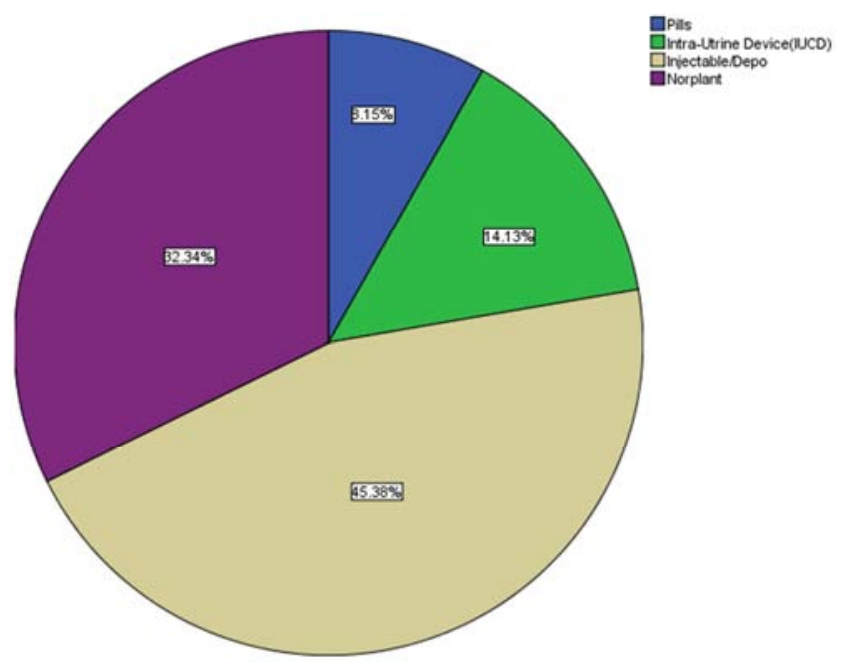

Figure 1. Characteristics of women by the type of family planning used in Arbaminch town, Gamo Gofa, Southern Ethiopia, March, 2013.

\subsection{The Effect of Family Planning Use}

In this study, $34.8 \%$ of respondents reported that using $\mathrm{F} / \mathrm{P}$ methods could improve household economy, while $27.7 \%$ of them reported that it helps for improving the family health status. The rest $(38 \%)$ of women indicated that it improves both family health and household economy.

Of all the respondents, $94.8 \%$ reported that $\mathrm{F} / \mathrm{p}$ could be used to reduce fertility/household size. The majority (91.6\%) felt strongly that they have actually observed the effect of $F / P$ in reducing fertility/family size.

In the current study, 245(66.6\%) of respondents reported that they had no illness following F/P use. Among those women $(33.3 \%)$ who reported to have had some form of illnesses, more than half $(53.3 \%)$ of them had contracted different communicable diseases followed by reproductive health problems (12\%). Following F/P use, $84.4 \%$ of clients had no history of hospitalization. A total of $286(77.7 \%)$ family planning users reported that their children had no morbidity in the last two years. The majority (91\%) of the respondents reported that their children were not admitted to hospital. This is also supported by the qualitative study. One of the discussant has said that "I have never seen any kind of disadvantage (morbidity or hospitalization) in my life following the use of $F / P$; this has been because of my good nutritional habit."
In this study, the main sources of household income reported by the respondents were monthly salary $(47.3 \%)$ followed by wage from daily labor $(26.9 \%)$, micro business (18.2\%) and farming (7.6\%). According to the findings of this study, the actual increase on household income following the use of F/P methods accounts for about 55.7\%.

\subsection{Test of Association between Selected Variables}

The association between some selected variables was made by using chi square test. A cross tabulation was made between the type of family planning used and the overall household economy (income). Accordingly, the result was found to be statistically significant at $p$-value of 0.03 with chi square $\left(\chi^{2}\right)$ value of 4.31 . Similarly, the association between family size grouped and educational status was found to be statistically significant at p-value of 000 with chi square $\left(\chi^{2}\right)$ value of 37.942 . There was also an association between awareness of the respondents about the importance of family planning use in improving household economy and the overall increase in household income $\left(\chi^{2}=9.698\right.$, p-value $=$ 0.002).The variable family planning used to reduce fertility/family size was also found to be significantly associated with the overall increase in household income $\left(\chi^{2}=6.489, p\right.$-value $\left.=0.039\right)$. There are other variables that have a significant association with the overall increase in household economy (income). These are actually observed the effect of family planning in reducing fertility/family size $\left(\chi^{2}=5.164, p\right.$-value $\left.=0.023\right)$, type of illness $\left(\chi^{2}=6.082\right.$, pvalue $=0.048)$, the impact of $\mathrm{F} / \mathrm{P}$ on the source and level of household income $\left(\chi^{2}=80.483, \mathrm{p}\right.$-value $\left.=0.000\right)$ and age group $\left(\chi^{2}=9.937\right.$, $\mathrm{p}$-value $\left.=0.019\right)$.

\subsection{Estimation of the Logistic Regression Model and Analysis of Result}

\subsubsection{Estimation of Binary Logistic Regression Model}

In this study, binary logistic regression was used because the outcome variable was found to be dichotomous as yes/no. Before applying the final multiple logistic regression models with ten covariates for the intended purpose it has been assessed and diagnosed for all possible model inadequacies.

The multiple logistic regression coefficients were estimated using the maximum likelihood estimation method implemented in the SPSS package. The results are displayed in Table1.

Table 1. Variables in the equation for the overall increase on household income among women in Arbaminch, Gamo Gofa, Southern Ethiopia, March, 2013.

\begin{tabular}{|c|c|c|c|c|c|c|c|c|}
\hline \multirow{2}{*}{ S. No } & \multirow{2}{*}{ Variables } & \multirow{2}{*}{ B } & \multirow{2}{*}{ S.E. } & \multirow{2}{*}{ Wald } & \multirow{2}{*}{ Sig. } & \multirow{2}{*}{$\operatorname{Exp}(B)$} & \multicolumn{2}{|c|}{$95.0 \%$ C.I. for EXP(B) } \\
\hline & & & & & & & Lower & Upper \\
\hline 1 & Total number of children & -.647 & .327 & 3.923 & .048 & .524 & .276 & .993 \\
\hline \multirow[t]{4}{*}{2} & $\begin{array}{l}\text { Impact of } \mathrm{F} / \mathrm{P} \text { on the source and level of } \\
\text { household income }\end{array}$ & & & 20.747 & .000 & & & \\
\hline & Medium & -.685 & 1.771 & .150 & 699 & .504 & .016 & 16.209 \\
\hline & Low & -3.597 & 1.789 & 4.043 & .044 & .027 & .001 & .913 \\
\hline & No impact & -4.316 & 1.939 & 4.955 & .026 & .013 & .000 & .597 \\
\hline \multirow[t]{3}{*}{3} & Frequency of hospitalization of respondents & & & 8.360 & .015 & & & \\
\hline & Twice & -1.363 & 1.081 & 1.591 & .207 & .256 & .031 & 2.128 \\
\hline & Trice and above & -3.387 & 1.260 & 7.225 & .007 & .034 & .003 & .400 \\
\hline 4 & Reasons for $\mathrm{F} / \mathrm{P}$ use & & & 6.385 & .041 & & & \\
\hline
\end{tabular}




\begin{tabular}{|c|c|c|c|c|c|c|c|c|}
\hline \multirow{2}{*}{ S. No } & \multirow{2}{*}{ Variables } & \multirow{2}{*}{ B } & \multirow{2}{*}{ S.E. } & \multirow{2}{*}{ Wald } & \multirow{2}{*}{ Sig. } & \multirow{2}{*}{$\operatorname{Exp}(\mathbf{B})$} & \multicolumn{2}{|c|}{ 95.0\% C.I. for EXP(B) } \\
\hline & & & & & & & Lower & Upper \\
\hline & Improves household economy & .013 & .270 & .002 & .962 & 1.013 & .596 & 1.720 \\
\hline & Both improve & .565 & .250 & 5.125 & .024 & 1.760 & 1.079 & 2.871 \\
\hline 5 & $\begin{array}{l}\text { Actually observe the effect of } \mathrm{F} / \mathrm{P} \text { on their } \\
\text { fertility reduction }\end{array}$ & -1.671 & 1.483 & 1.270 & .260 & .188 & .010 & 3.441 \\
\hline \multirow[t]{4}{*}{6} & What does the meaning F/P? & & & 3.881 & .275 & & & \\
\hline & Limiting family size & .515 & 1.185 & .189 & .664 & 1.674 & .164 & 17.080 \\
\hline & Avoiding unwanted pregnancy & -1.083 & 1.192 & .825 & .364 & .339 & .033 & 3.504 \\
\hline & Both & .752 & .918 & .671 & .413 & 2.121 & .351 & 12.832 \\
\hline 7 & Family size & .357 & .258 & 1.916 & .166 & 1.429 & .862 & 2.370 \\
\hline 8 & Type of F/P use & .443 & .213 & 4.296 & .038 & 1.557 & 1.024 & 2.365 \\
\hline 9 & Occupation & & & 8.669 & .070 & & & \\
\hline \multirow{10}{*}{10} & Merchant & -1.233 & 1.113 & 1.228 & .268 & 291 & .033 & 2.582 \\
\hline & House women & -2.496 & 1.089 & 5.258 & .022 & .082 & .010 & .696 \\
\hline & Student & -1.076 & 1.244 & .748 & .387 & .341 & .030 & 3.904 \\
\hline & Daily laborer & -4.969 & 1.776 & 7.828 & .005 & .007 & .000 & .226 \\
\hline & Educational level & & & 5.958 & .202 & & & \\
\hline & Read and write & -1.262 & 1.055 & 1.431 & .232 & .283 & .036 & 2.238 \\
\hline & Primary & -1.576 & .924 & 2.910 & .088 & .207 & .034 & 1.264 \\
\hline & Secondary & -2.721 & 1.199 & 5.145 & .023 & .066 & .006 & .691 \\
\hline & Collage and above & -3.162 & 1.481 & 4.562 & .033 & .042 & .002 & .771 \\
\hline & Constant & 5.485 & 3.180 & 2.976 & .084 & 241.127 & & \\
\hline
\end{tabular}

\subsubsection{Results from the Analysis of the Regression Model}

The Binary logistic regression model estimates were made in order to determine factors that affect overall household income. Table 1 shows that seven factor scores out of ten are significant at 5\% level of significance. Note that Exp (B) gives the odds ratios for each variable. The odds ratio and confidence interval were computed to determine the degree of association between selected explanatory variables and outcome variable.

Among the socio-economic variables: education, occupation, family size, and total number of children were entered into the model. Accordingly, the odds ratio for education category $(3=$ Secondary School) was $0.066(95 \%$ $\mathrm{CI}=0.006,0.691)$, while the odds of education category $(4=$ college and above) was $0.042(95 \% \mathrm{CI}=0.02,0.771)$. These values indicate that a change in educational status is being associated with the odds of overall increase in the household income following by $\mathrm{F} / \mathrm{P}$ use and by a multiplicative factor of 0.066 and 0.042 , respectively.

Actually observing the effect of F/P in reducing household size were found to be statistically insignificant and has a negative sign in relation to the overall household income.

With respect to occupation, even though the whole effect of occupation was not statistically significant, some of the occupation categories such as housewives and daily laborers were having statistically significant relationship with the overall increase in the household income.

The odds ratio for the total number of children was 0.524 $(95 \% \mathrm{CI}=0.276,0.993)$. For one unit change in the total number of children increases the odds of yes to the overall increase in the household income increases by 0.523 . This indicates that having a large number of children has a negative effect on the overall increase in the household income.

In this study, respondents were asked to indicate the impact of F/P on the source and level of their household income. Accordingly, those respondents who pointed out the impact as either low or no were the ones less likely to attain an overall increase in the household income as compared to those who indicated the impact to be high. Those women who indicated the impact of $\mathrm{F} / \mathrm{P}$ as low and have no impact were 0.027 and 0.013 times less likely to achieve an overall increase in their household income than those who indicated as high, respectively.

The type of family planning methods used was found to be significantly associated with the overall household income. Those respondents who used long acting type of $\mathrm{F} / \mathrm{P}$ methods were 1.557 times more likely to attain the overall increase in their household income. Those respondents who mentioned their reason of F/P use as a means for improving both health and economic status were 1.79 times more likely to attain the overall increase in their household income than those who mentioned only as a means for improving health status.

\section{Discussions}

Around $44 \%$ of women recognized the use of family planning as a means to ensure child spacing followed by $32.3 \%$ of those who reported as a means of limiting family size. This is comparable with other similar study that was conducted in Dukem town which reported $48.6 \%$ of women mentioned the use of $\mathrm{F} / \mathrm{P}$ as a means of child spacing followed by $32.3 \%$ who mentioned FP as a means for limiting the family size [8].

Majority (94.8\%) of women reported that $\mathrm{F} / \mathrm{p}$ could be used to reduce fertility/household size. Out of $349(94.8 \%) \mathrm{F} / \mathrm{P}$ clients who said yes to the effect of F/P in reducing fertility, $90.2 \%$ had actually observed the effect of family planning in reducing their own fertility/family size. Among the respondents who actually witness the effect of family planning in reducing their fertility/family size, $31.8 \%$ identified improving household economy as a reason for $\mathrm{F} / \mathrm{P}$ use.

There are limitations in finding more empirical evidences 
that might be used for comparison with the current findings. However; there are some findings that can be used for comparison with the major findings of this study. For example, Rhonda et al (2009) stated that the growing use of contraception around the world leads to a marked reduction in fertility thus offered tremendous life saving benefits at the household and community level [9].

The result of this study also showed that, among the respondents who had actually observed the effect of $\mathrm{F} / \mathrm{P}$ in reducing fertility, the majority $(63.3 \%)$ of them reported that they had only one child with the age of less than five years. This is also in line with the finding with the result from the longitudinal study that was conducted in Bangladesh on the Matlab program. The finding from Matlab program study suggested that women in the program area were having fewer children; an average of 1.5 fewer children as compared to women in the comparison area. It also showed that households and women in the FPMCH Program areas were economically better off $[10,11]$.

With regard to morbidity and hospitalization, this study revealed that $245(66.6 \%)$ of the respondents reported that they had no illnesses following the use of $\mathrm{F} / \mathrm{P}$ within the last two years. In addition, it was indicated that $84.4 \%$ of $\mathrm{F} / \mathrm{P}$ clients had no history of hospitalization within the last two years. This is also supported by the findings from one study that was conducted in Indonesia. It was reported that women using family planning and had only one or two children felt that they have no health problems and they are "feeling okay" than those with more than two children [12].

According to the findings of this study, the actual increase in the income of the household following the use of F/P service accounts for about $55.7 \%$. Out of these, the proportion of women who observed and reported the overall increase on household income attributed to the use of $\mathrm{F} / \mathrm{P}$ has been $41.8 \%$.

The result of this study demonstrated that family size has an association with women empowerment (education). The total number of children had a significant association with the overall increase in the household income. This shows that having a large number of children has a negative effect on the overall increase in the household income. This is supported by the evidences indicated by United Nations report. It was stated as high fertility may have a possible and an important effect on the health and economic wellbeing of a family and a nation at large $[13,14]$.

\section{Conclusions and Recommendations}

In this study, the majority of F/ P clients had actually observed the effect of family planning in reducing their own family size. In general, most of the clients had reported the effect of $\mathrm{F} / \mathrm{P}$ in improving their household economy (income). The type of $\mathrm{F} / \mathrm{P}$ method, the total number of children, the frequency of hospitalization and the reason for using family planning were some of the potential predictors of household income. A strategy has to be designed to reach women who had less awareness about the effect of family planning in improving household economy. An emphasis has to be given to the way how the coverage and utilization of long term family planning methods can be improved.

\section{Acknowledgments}

We would like to forward our gratitude to Civil Service University for providing such an opportunity to conduct the current study. Our sincere and deepest gratitude goes to Gamo Gofa Zone Health Department, Arbaminch Town Health Office, Supervisors, data collectors and respondents.

\section{References}

[1] Willard Cates Jr. et al., "Family Planning and the Millennium Development Goals," Science 329, no. 5999(2010): 1603.

[2] Karin R, et al, Integrating family planning and maternal and child health care: saving lives, money, and time, Population Reference Bureau, 2011.

[3] Ministry of Finance Economy Development report on population, 2011.

[4] The Transitional Government of Ethiopia, The population policy of The Transitional Government of Ethiopia. Addis Ababa, 1993.

[5] World Bank (2011) report.

[6] C. Lloyd and S. Amin (1998). Women's lives and fertility decline: Some lessons from Bangladesh and Egypt, Working Paper No. 117. New York: Population Council, 1998.

[7] Lundberg, S., \& Pollak, R. A. (2007). The American family and family economics. Cambridge, Mass.: National Bureau of Economic Research.

[8] Chala Wegi (2011). Agreement and concordance regarding fertility intention and family planning utilization between married couples in Dukem town, Oromia Special Zone (Unpublished).

[9] Rhonda Smith et al. Family Planning Saves Lives, 4th ed. Washington, DC: Population Reference Bureau, 2009.

[10] James G and Maj-Lis V. Family Planning and Economic WellBeing: New Evidence from Bangladesh. Population Reference Bureau, 2009.

[11] Shareen Joshi and T.paul Schultz (2012), Family planning and women's and children's health: long term consequences of an outreach program in Matlab, Bangladesh. IZA DP No. 6551.

[12] Irwanto, Poerwandari EK, Prasadja H, et al. In the Shadow of Men: Reproductive Decision-Making and Women's Psychological Well-Being in Indonesia, Final Report for the Women's Studies Project. Research Triangle Park, NC: Atma Jaya Catholic University and Family Health International, 1997.

[13] United Nations (2011) report on fertility, 2011.

[14] Luaren S (2011). Family planning and maternal health: the effect of family planning on maternal health in the democratic republic of Congo. 